\title{
Application of forgiveness in rehabilitation psychology: a positive option for change
}

\begin{abstract}
Throughout the past 25 years, forgiveness has been a part of psychology and studied within many populations. However, forgiveness has not been considered nor promoted as a helpful skill or approach when counseling persons with disabilities or in the rehabilitation counseling/psychology profession at large. In an effort to change this trend by educating the profession on the importance and relevance of forgiveness to the practice of rehabilitation psychology, readers are afforded the opportunity to learn about forgiveness, its application and relevance to persons with disabilities, and to further their understanding of how forgiveness can be conceptualized and explored. Provided in this article is a proposed forgiveness model which can be used to assist professionals in the exploration of forgiveness among the people they serve. Following this model is an applied case study and professional implications.
\end{abstract}

Keywords: forgiveness, rehabilitation, disability, forgiveness models, rehabilitation psychology, counseling, rehabilitation counseling

\author{
Volume 4 Issue 4 - 2019
}

\author{
Susan Stuntzner,' Jacquelyn A Dalton, ${ }^{2}$ Angela \\ MacDonald ${ }^{3}$ \\ 'Rehabilitation Services and Counseling and Student Success \\ Services, University of Texas Rio Grande Valley, Southwestern \\ Oregon Community College, USA \\ ${ }^{2}$ Clinical Rehabilitation \& Clinical Mental Health Counseling \\ Program, East Central University, USA \\ ${ }^{3}$ Rehabilitation Counseling \& Human Services, University of Idaho, \\ USA
}

Correspondence: Susan Stuntzner, Rehabilitation Services and Counseling, Educational Support Services, University of Texas Rio Grande Valley, Southwestern Oregon Community College, USA, Tel 54I-888-1578, Fax 54I-888-723I, Email Susan.stuntzner@utrgv, susan.stuntzner@socc.edu

Received: August 07, 2019 | Published: August 16, 2019

\section{Introduction}

With the advent of the positive psychology movement - and its focus on strengths following change, challenges, and/or adverse situations-psychologists, counselors, and other helping professionals are beginning to explore the importance of studying, understanding, and focusing on factors and traits that help people move forward in a positive fashion following difficult life events. ${ }^{1}$ Some of the positive psychology literature is beginning to consider the strengths and abilities of persons with disabilities (PWDs) along with what needs to be present for people to interpret their life and set of circumstances in a more positive or constructive way. ${ }^{2}$ Within the context of positive psychology and coping-especially as it applies to the unique set of circumstances surrounding PWDs-scholars have an opportunity to consider forgiveness as a positive coping strategy that is learned, cultivated, and/or enhanced and contributes to overall personal wellbeing as well as a positive therapeutic intervention.

While forgiveness has been discussed openly as a part of psychology $^{3}$ and in the pursuit of religious or spiritual practices and beliefs, ${ }^{4-6}$ it has been scantly considered and explored throughout the rehabilitation psychology profession. Similarly, few articles have been published within the rehabilitation profession that explore and educate counselors and psychologists about the relevance and application of forgiveness to disability and the needs of persons with disabilities. ${ }^{7-9}$

Understanding the relevance of forgiveness to persons with disabilities is essential considering the multiple layers of injustice, barriers, and poor treatment experienced by these individuals and the amount of negativity and changes they are asked to cope with following a disability. Consideration of these issues by rehabilitation professionals is important to promote inner healing and positive coping and well-being; yet, some may not feel as comfortable as they would like to when it comes to forgiveness or strategies that may be employed to further facilitate the discussion and exploration of forgiveness. In an effort to change this trend and to further rehabilitation professionals' understanding of forgiveness and its relevance to the profession, the following article was written. Throughout, professionals are educated about forgiveness, its relevance and applicability to persons with disabilities, and strategies about how forgiveness can explored through the use of a forgiveness process model. In addition, a case study is provided to further encourage professionals' conceptualization and application of forgiveness to the coping and adaptation process and to the people they serve.

\section{Case study perspective on forgiveness}

The following example is provided to help illustrate the forgiveness model and its relationship to a person's coping process. This case study may be beneficial to some readers in providing a situational context upon which to focus the specific aspects which will be introduced and examined throughout this article. After professionals review the case study, they are asked to consider the six stages and the 23 guidelines provided in Table 1. Questions for reflection are provided later in this article to further stimulate the reader's exploration and understanding of the potential benefits and applications of forgiveness in their work with PWDs.

\section{The case of sami}

Sami is a 32-year-old female with a spinal cord injury at level T-6 and is a new client on your caseload. She has lived with her injury for about two years and is paralyzed from the waist down. Previously, you have met with her twice, and both times you noticed she is quite emotional and easily aroused. During the initial intake, you learned that a drunk driver hit her and her fiancé who acquired a traumatic 
brain injury. Sami reported that the driver was a minor and that repercussions to the driver were minimal. Sami stated that the driver was sentenced to jail for two weeks, 3 months of probation, and then was given the opportunity to have the whole charge and situation erased from his personal record. In her mind, this was not justice or fair as the driver was not physically injured, and had not taken steps to apologize or account for his actions. Furthermore, Sami shared the driver basically got a 'slap on the wrist' for his crimes and was able to resume his old life and go on as if nothing happened. Meanwhile, Sami and the life of her fiancé have been changed forever.

Sami initially shares pieces of this story and appears to still be emotionally and psychologically tormented primarily due to the injustice and unfairness of the situation as well as the fact her life completely changed. Next, she reports wanting to get a job and find something she can do for a long time given she is not able to walk. As the rehabilitation professional, you want that for her too. However, every time you meet with her, she spends much energy and time discussing what is not going right in her life, telling you how she is angry and the reason(s) for it, and sharing stories about the way people treat her since she is in a wheelchair. She also talks about how her family is not emotionally supportive, and she is furious at God. Her feelings are compounded by the fact that she believes in God and finds spirituality critical; yet, she does not appear to feel supported by many members of her church.

Today, when she comes to see you, Sami also discloses about her frustrations with meeting new people as she and her fiancé broke up. Eventually, she sighs and says, "It's just not fair! I try so hard to get my life going, and I face all of these barriers, yet nothing seems to work right. I feel alone and unsupported. I am so angry at God! I can't even breathe. I am not sleeping, eating, or getting out much. I feel depressed and anxious much of the time. It all seems pointless. The way people treat or react to me due to the wheelchair has been especially challenging of late. When I think about this, how is it I am ever going to find a job or become employed? I mean employers are people with biases, and they discriminate too. You know they do!"

\section{Definition of forgiveness}

Forgiveness is frequently defined and understood as an individualized and personal process whereby the person hurt and offended by someone else reduces negative thoughts, feelings, and behaviors (i.e., resentment, desire for revenge) toward the offending person and replaces them with more positive ones including tolerance, patience, compassion, and benevolence $e^{10-12}$ even if the person does not deserve it. Forgiveness is a way for the offended individual to face the hurt and injustice experienced, to reframe the event and conflict from a more open and expanded view,,$^{13}$ and to discover some of the many benefits he or she may personally experience by making this choice. In addition, forgiveness is a process which does not occur in a linear fashion, happen quickly, and one that often takes time depending on the interpretation, severity, and repeated nature of the offense endured. ${ }^{14}$

Forgiveness is a personal choice, and a targeted goal people work toward when a deep hurt or injustice has occurred between two people. ${ }^{15}$ While forgiveness encapsulates something that involves the existence of hurt or betrayal between two people, the authors posit that forgiveness may also be related to the need to forgive oneself, events that happen on a constant basis, or a higher being such as God..$^{16,17}$ Part of this reasoning is due to the fact that some people experience "repeated" hurts, insults, or injustices by either known or unknown individuals. Some encounter continued and often repeated offenses about how they are perceived and/or treated by society or strangers who are not familiar or comfortable with the presence of disability. ${ }^{18}$ Such situations lead some people to the discovery that they have a need to forgive "a recurring event" as a single person or entity is not the sole cause. ${ }^{19}$

\section{Empirical research on forgiveness}

Forgiveness has been discussed theoretically and studied empirically throughout the research with many different populations. In many instances, forgiveness has been offered and delivered as a multi-week intervention to aid in the reduction of negative thoughts and feelings and the promotion of positive ones (i.e., Enright's Forgiveness Process Model). Other studies approach forgiveness as a workshop; something worked on through essay writing, or a combination thereof, ${ }^{20}$ as a brief intervention, ${ }^{21}$ or through the study of factors related to forgiveness.

\section{Enright's forgiveness model}

Forgiveness scholars, Enright and Fitzgibbons, ${ }^{10}$ discuss one forgiveness model that has been well studied throughout the research and forgiveness intervention studies. According to these scholars, forgiveness is described as a process that occurs according to four phases and 20 units. People learning to forgive are believed to go through the Uncovering Phase, the Decision Phase, the Work Phase, and the Deepening Phase. Within each phase are units or steps people may experience as a part of each stage.

Throughout the intervention research, people are taught about forgiveness, what it is, and the adverse effects of not forgiving and how it may impact them presently. The intervention provides individuals with the opportunity to explore and discover negative thoughts and feelings held which may prevent them from moving on. During the Uncovering Phase, much of this work is identified. Once people become aware of their current thoughts and feelings and the impact these have on their overall functioning and well-being, they may move into the Decision Phase. During this phase, people consider and decide if forgiveness will aid in healing and help them move forward. If so, they often make a commitment to work on forgiveness, as it is not easy to forgive when grave offenses occur. Following the Decision Phase is the Work Phase.

The Work Phase is where people learn about forgiveness; strive to work towards it and attempt to let go of the negativity held toward the offender by learning to reframe the offense, the offender, and their personal pain. Throughout this phase, people are encouraged to consider viewing the offender in another, more compassionate way. ${ }^{22}$ During the Outcome/Deepening Phase, people work on reframing the hurt and offense, and on their inner self enough that they can find meaning in the pain or severe event ${ }^{23}$ and move on with life in a positive manner.

Understanding this process is essential for professionals wanting to implement this model throughout the research or as an intervention. Forgiveness scholars have utilized the forgiveness process model with several populations. For example, Enright and Fitzgibbons ${ }^{10}$ discuss research that has taken place among individuals with substance abuse issues, cancer ${ }^{24}$ adult children of alcoholics ${ }^{25}$ and individuals living with cardiac issues. ${ }^{27}$ Additional forgiveness research studies 
that support the use of the forgiveness process model include work completed among people with spinal cord injury ${ }^{20,26}$ and among women with fibromyalgia who also experienced emotional abuse..$^{28}$

Findings from these studies provide support for the notion that forgiveness helps reduce negative emotions such as anger, depression, and anxiety ${ }^{8,25,27}$ and decrease phases of negative coping and adaption among persons with spinal cord injury. ${ }^{20,26}$ Forgiveness also improves self-esteem and personal relationships ${ }^{25}$ problem-solving skills, ${ }^{27}$ restores hope ${ }^{24}$ and further contributes to peoples' ability to forgive. The benefits suggested by these studies are in line with the general needs of PWDs regardless of disability type and onset.

\section{Factors related to forgiveness}

Beyond the work conducted by Enright and colleagues, forgiveness has also been studied among other populations such as people with traumatic brain injury, ${ }^{29}$ posttraumatic stress disorder, ${ }^{30}$ low chronic back pain, ${ }^{31}$ and cardiac conditions. ${ }^{32}$

Similarly, much of the forgiveness research is focused on factors related to or associated with forgiveness rather than a particular approach or intervention. From these studies, forgiveness appears to be a potential variable in the adjustment to disability process for persons with spinal cord injury. ${ }^{33}$ Forgiveness is also found to have an influence on peoples' health and life satisfaction, ${ }^{34}$ perceived stress, ${ }^{32}$ and to be associated with resilience among persons with traumatic brain injury. ${ }^{29}$

\section{Framework to understand forgiveness in the context of disability}

Forgiveness has much relevance to persons with disabilities as a life skill to help deal with hurt and offenses, a therapeutic process or intervention to aid in healing, a means to cope with and move past the disability and to promote overall well-being, and as a model which can be used or developed as a part of the therapeutic relationship. To assist rehabilitation professionals in understanding the necessity and value of forgiveness as a vital component of the rehabilitation and recovery process, forgiveness as it relates to the context of disability is discussed in further detail in the following sections.

\section{Forgiveness: a skill or an intervention?}

Rehabilitation professionals wanting to understand forgiveness and its utility to the rehabilitation profession may wonder whether forgiveness is an intervention or if it is a skill people have and can cultivate. The authors' perspective is that forgiveness is a process which is both a skill and a therapeutic intervention. As a skill, forgiveness may be applicable to the PWD who expresses a theme of or related to anger, resentment, grief, loss, betrayal, oppression, and/or humiliation in order to contribute to the improvements and building up of healthy coping skills. Utilizing the process of forgiveness as an intervention has the potential to introduce the concept of forgiveness to the PWD as a coping skill and a method of processing and understanding both the changed world within them and the changed world around them.

When forgiveness is described and taught as an educational process ${ }^{10}$ people are asked to consider a person (or a repeated situation/ offense) so that an identified "individual" known or believed to have caused harm to the forgiver can be determined. Identification of the offense or offender helps the offended person work on forgiveness by having someone or, in some instances, something to apply the learned process to following the recollection of the hurt or offense. It gives the "forgiver" a place from which to start and later determine if progress in learning to forgive will take place.

As people work through the recognition of painful thoughts and feelings (i.e., mental rumination, not being able to release painful thoughts and feelings, anger), they begin to understand the ways they inhibit moving past the offense and in finding peace and a sense of resolution with what took place. Further, some forgiveness scholars stress the importance of educating a person about forgiveness, the ways it may benefit them should they practice it, as well as encourage the practice of skills or strategies to help forgiveness materialize in their life. One such way to accomplish this is to make the decision to forgive ${ }^{10}$ and work to change one's thoughts and feelings toward the offender. This process is often encouraged throughout forgiveness intervention studies to help people learn to view the offending person in a more loving and compassionate manner since the act of forgiveness and compassion "frees" the offended person emotionally and mentally from the internal pain and bondage. As people work through the process, many learn to do more than release themselves from the pain; they learn to find meaning in their situation, ${ }^{35}$ realize they are not the only ones hurting or to have gone through an event. Some may even come to realize they have begun to cultivate more positive thoughts, feelings, and ways of living. ${ }^{19}$

Related to the process of forgiveness is the fact that it cannot be "willed" or forced. When people try to make themselves forgive, and they are not ready, able, or willing, they tend to experience the opposite such as feelings of anger and resentment. ${ }^{36}$ Understanding the adverse effect of prematurely encouraging forgiveness can help rehabilitation professionals understand that forgiveness sometimes involves a "readiness" step, and it is this component of the forgiveness process that is essential for preparing people to "let go" or release the inner turmoil they presently experience. ${ }^{19}$ Similarly, people may try to forgive but find it is too hard. As a result, they may feel stymied and unable to move forward until some additional preparatory therapeutic work is complete.

For some, forgiveness may be viewed as a skill. In this instance, people who practice or desire to practice forgiveness are afforded the opportunity to learn techniques (which may or may not be a part of the selected forgiveness process; Stuntzner, 2015b) ${ }^{37}$ People who learn how to forgive as an approach to dealing with painful hurts and offenses can access specific skills to aid them in forgiving a hurt or offense. For instance, someone may cultivate specific skills such as mindfulness, self-compassion, compassion for others, or resilience through a workshop, training, course, or psychosocial intervention and throughout the skill acquisition process come to realize that forgiveness may be a component of the skill they are trying to learn or enhance. ${ }^{37,38}$ Throughout their attempts to access these learned or cultivated skills and abilities, people may realize they also need to forgive to enhance further their mindfulness, self-compassion, or resilience.

\section{Relevance of forgiveness to disability}

Forgiveness has much relevance and applicability in the lives and experiences of persons with disabilities. ${ }^{39}$ Forgiveness can help individuals who have been emotionally, psychologically, physically, or spiritually hurt or offended. In particular, as previously discussed throughout forgiveness intervention research studies, forgiveness can reduce peoples' anger, anxiety, and depression and improve numerous 
positive aspects of their life (i.e., self-esteem, forgiveness, adjustment to disability). Thus, the forgiveness research available suggests it can have an invaluable role in healing peoples' hurts and offenses, and that it may have the potential to provide similar benefits for persons with disabilities.

Understanding the power of forgiveness and its role in aiding people in positive functioning is essential as it may be a factor that aids in better coping and adaptation. For example, Willmering ${ }^{33}$ in her qualitative study among persons with spinal cord injury found that many people reported forgiveness as a means to assist them in positive coping and adjustment. Further, Stuntzner ${ }^{20}$ in her study among individuals with spinal cord injury proposed a theoretical model (Figure 1) that illustrated the possible relationship between forgiveness and adjustment to disability. According to this model, persons with disabilities can work through one of two coping processes (i.e., forgiveness or adjustment to disability) to reach a better state of emotional and psychological functioning. When persons with disabilities elect to work on forgiveness, it is understood that they may have some negative thoughts, feelings, and personal pain (i.e., anger, depression, anxiety) as a part of the process and by working through them they can increase their levels of forgiveness, possibly improve their coping abilities, and generate more positive thoughts, feelings, and behaviours. Similarly, people who decide to work on the coping and adaptation process, first, may reduce their negative thoughts, feelings, and behaviours; possibly improve their ability to forgive, and learn to cope with their disability. Conceptualizing forgiveness and coping with disability as parallel but equally effective processes can be useful to rehabilitation professionals in understanding that there is more than one route to consider and practice forgiveness and as people work on their hurts, pain, and personal issues, some may discover that forgiveness is a part of the process and can aid them in the cultivation of positive thoughts, feelings, and behaviours.

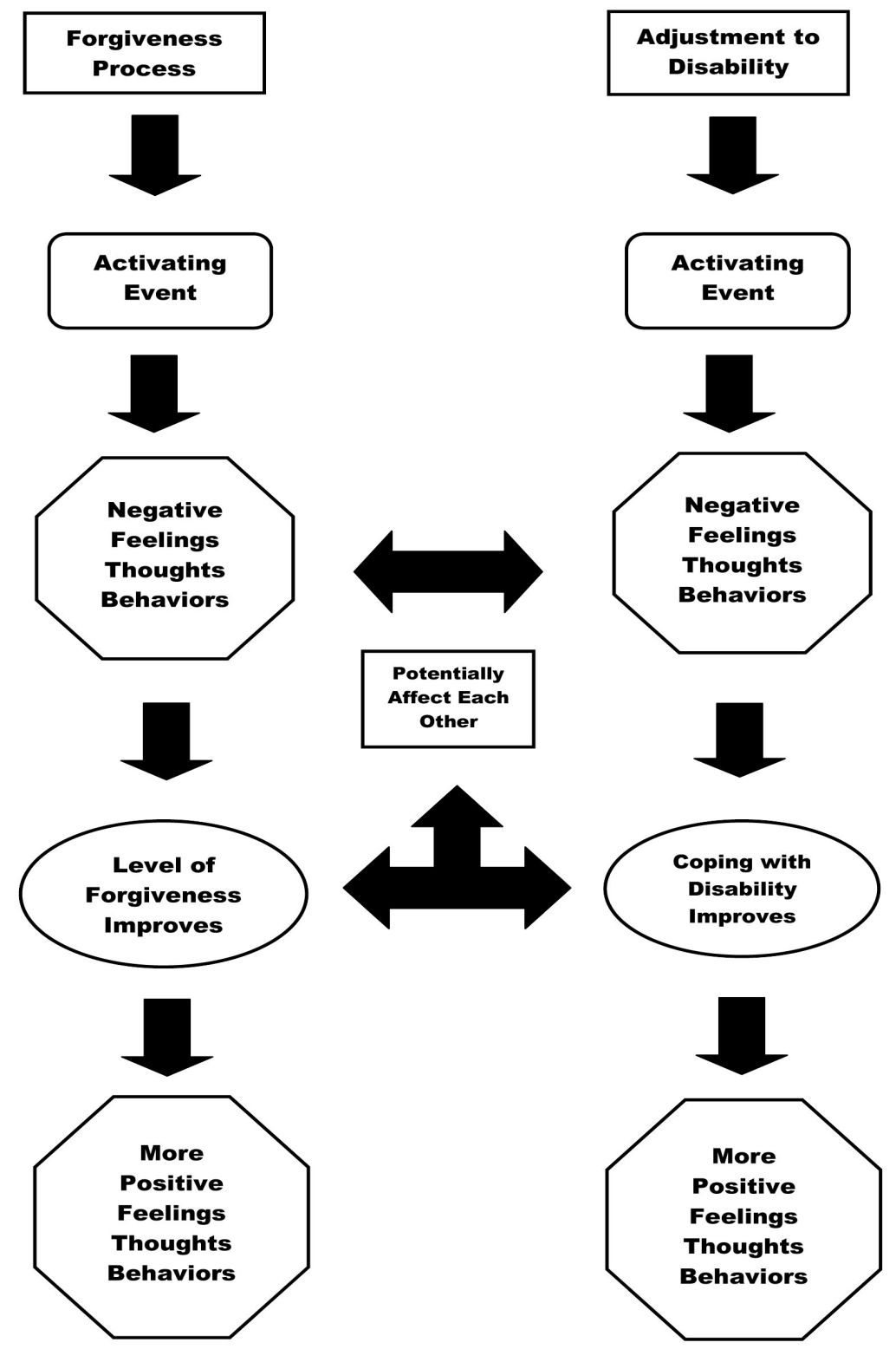

Figure I Relationship between forgiveness and adjustment to disability. 
Given the fact that persons with disabilities sometimes experience hurts and offenses from multiple sources (i.e., society, persons without disabilities, professionals, employers), some people may eventually discover that they harbor or have internalized negative thoughts, feelings and resentments - all of which impact them in negative ways. ${ }^{39}$ Others may realize they blame themselves or God or some other external entity for real or perceived injustices and offenses. Well-documented and discussed hurts, offenses, and difficulties encountered by persons with disabilities include: negative societal messages and treatment of persons with disabilities; ${ }^{18,40}$ causes or perceived causes of one's disability (i.e., self-blame, anger at God), discrimination, marginalization, and social injustice; ${ }^{39}$ significant losses and changes related to the presence of disability (i.e., loss of employment, finances, relationships, inadequate care giving; Marini, Glover-Graf, \& Millington, 2012; Smart, 2009; Stuntzner, 2015a); ${ }^{40,41,42}$ repeated hurtful and derogatory social or interpersonal experiences ${ }^{19}$ family coping or the inability to cope with the family member's disability; and challenges in practicing self-forgiveness as it relates to one's coping process.

While each of these issues may be a part of the coping and adaptation process and life following a disability, they are not easy ones to address. Any of them, alone or in combination with others, can prevent or inhibit persons with disabilities from coping as well as they desire.

Similarly, the concerns mentioned earlier can cause or further perpetuate negative thoughts, feelings, and resentments-all of which may influence the coping and adaptation process. For some of these issues and offenses, forgiveness and learning to forgive may provide people with an alternative way of life.

\section{Exploration of forgiveness in rehabilitation psychology}

Many forgiveness models exist throughout the literature. In these models, forgiveness scholars ${ }^{10,43,44}$ discuss steps or phases through which people progress as they work on forgiveness. These models stress the importance of identifying the hurt or offense that has occurred, recognizing the presence of negative thoughts and feelings, learning to forgive as it relates to the transgression, and experiencing the benefits or a better way of life due to forgiveness. However, forgiveness scholars have not developed or proposed forgiveness models or approaches specifically related to the needs and experiences of persons with disabilities. As a result, the authors developed a model for rehabilitation professionals to consider and use as they explore forgiveness in their work with individuals with disabilities (Table 1).

Table I Exploration of forgiveness in rehabilitation psychology

\section{Forgiveness Phases for Rehabilitation Professionals to Consider}

\section{Hurt or Offense}

Consider if a counselor, psychologist, or an allied-helping professional would be helpful for support and encouragement as a part of the exploration process.

2 Understand that disability is

3 Identify the people or situations that cause the individual mental and emotional pain.

4 Consider various ways peoples' lives change or are negatively impacted following a disability.

Society's attitudes and treatment of persons with disabilities..$^{40}$

Another person's actions or words (i.e., overt lack of acceptance due to the presence of disability). ${ }^{18}$

Repeated events that have a theme, but are not tied to one person (i.e., continuous negative experiences because a person is on social security and is not able to go to work). ${ }^{19}$

A reoccurring situation in the person's life (i.e., abuse, neglect, denied employment opportunities).

Beliefs and feelings held or internalized because of disability (i.e., disability acquisition). ${ }^{40}$

Negative thoughts or feelings held towards one's self (i.e., anger, self-blame) ${ }^{47}$

Difficulty trusting or believing in God (i.e., belief that God did not protect the person from harm).

5 Encourage the person to be patient throughout the process as it is not easy to look at hurt, pain, or offenses.

2 Coping Skills and Approaches

6 Explore whether or not the current way of coping with one's pain, hurt, and/or offense is working or helpful.

7 Examine if there are consequences or things happening as a result of the coping skills used.

8 Ask the person if he or she wants a "better" life and if so, what would that look like? ${ }^{38}$

9 Explore if the person is willing to do something else to improve the coping process and to heal.

3 Exploration of Therapeutic Options to Promote Healing and Forgiveness

I0 Discuss or list other choices and approaches the person could use.

II List benefits and limitations of each coping strategy.

How can this skill help the person heal and move forward as it relates to the forgiveness and healing process? 


\section{Forgiveness Phases for Rehabilitation Professionals to Consider}

Identify if there is a need to forgive or consider forgiveness as a part of the healing process. If there is, explore what the person needs

12 to help him- or herself forgive and work towards forgiveness (i.e., personal support, counseling, homework exercises, outside reading on forgiveness).

Increase understanding of forgiveness and how the presence of disability is associated with hurt and pain that sometimes require the exploration, practice, and cultivation of forgiveness.

\section{$4 \quad$ Barriers, Fears, and Obstacles that Inhibit Forgiveness}

4 Ask and consider throughout the cultivation of forgiveness if there are barriers, fears, or obstacles that inhibit progress towards forgiveness.

15 Determine if the person is willing or able to address these as a part of learning to forgive.

16 Identify strategies to reduce personal barriers and fears then use them as necessary.

$5 \quad$ Learn about Forgiveness and its Relevance to Living a Better Life

17 Educate the person on forgiveness and its relevance to living with a disability.

18 Explore the ways learning to forgive can enhance a person's life. ${ }^{37}$

19 Determine a starting point to address and apply information learned about forgiveness. ${ }^{19,37}$

20 Choose and practice strategies to promote forgiveness (i.e., prayer, journaling, cognitive reframing, reading books or information about forgiveness, forgiveness group or intervention).

\section{Cultivation and Integration Forgiveness Skills and Practices}

21 Foster understanding that forgiveness is not easy, takes time, but improves lives over time.

22 Encourage continued practice and cultivation of forgiveness as a part of the therapeutic relationship.

23 Discuss the ways a person's thoughts, feelings, behaviors, or experiences have improved since working on forgiveness. ${ }^{48}$

Table 1 suggests that forgiveness and the identification of the need for it as a part of the rehabilitation process can be broken down into six phases: (a) identification of the hurt or offense as it relates to living with a disability, (b) exploration of current coping skills and their ability to address a person's emotional and mental pain, (c) discussion of therapeutic options available to promote healing and forgiveness, (d) identification of personal barriers and fears which may inhibit progress towards forgiveness, (e) education and information about forgiveness and its relevance to living a better life, and (f) cultivation and integration of forgiveness throughout a person's life. Within each of these phases, 23 additional guidelines are illustrated to demonstrate the complexity of forgiveness as it relates to disability and the needs of persons with disabilities and to provide rehabilitation professionals with a framework from which to understand and approach forgiveness with the people they serve. Rehabilitation professionals wanting to approach forgiveness as a part of the rehabilitation process are encouraged to review and consider the coping needs and the topic of forgiveness as it relates to a person's coping and adaptation process.

\section{Questions for reflection: the case of sami}

After having exposure to both the case of Sami (mentioned earlier) and a comprehensive overview of the potential application of forgiveness in the rehabilitation process, the reader may have some thoughts on the presenting issues and the ways in which forgiveness might help Sami cope better (i.e., feel less angry and anxious, improve personal relationships) and work towards her goal of becoming employed (i.e., better attitude towards employers, coworkers). Before introducing the subject or implementing the intervention of forgiveness, professionals will want to consider how they will cultivate a therapeutic environment to address forgiveness. Professionals are encouraged to review the timing and readiness of the person to work on forgiveness as well as the strategies to best introduce forgiveness into the therapeutic dialogue as a means to heal emotional and psychological hurts.

Professionals working through the case of Sami, may find it helpful to consider questions they could ask themselves or the individual as both address forgiveness as a part of the rehabilitation process. These issues are not all encompassing, as professionals may elicit others that help the person (in this case, Sami) work on forgiveness. The questions provided are examples of some of those professionals can use to explore the need, relevance, and timing of forgiveness work as well as potential strategies and benefits.

Questions to reflect upon could include: (a) Hurt or Offense: What is the reported hurt or offense? How does this identified situation affect the person emotionally, mentally, physically, vocationally, and spiritually? (b) Coping Skills and Approaches: How well does the person's current coping skills work when dealing with emotional pain? Are there negative consequences experienced by the person due to the way he or she is currently coping? Does the person want a better life and if so, what does s/he say it would look like? (c) Exploration of Therapeutic Options: What are some coping skills the person could use to deal with the identified situation? What are the pros and cons of the skills used or chosen? Where does forgiveness fit into the identified hurt and situation? Is the painful offense or hurt directly or indirectly related to the person's disability? (d) Barriers, Fears, and Obstacles to Forgiveness: Does the person report any fears or concerns about working on forgiveness? What work can be done within the counselling relationship to reduce these barriers and fears? (e) Learn about Forgiveness and its Relevance: What strategies can be used to introduce and educate the person about forgiveness and its benefits to the individual? How can the person explore and actively apply forgiveness to their life? What are some strategies the person 
might use or find beneficial to promote forgiveness? (f) Cultivation and Integration of Forgiveness: What can be done in the therapeutic relationship to provide support as the person works on forgiveness? How has the person's life improved since working on forgiveness?

\section{Professional implications}

Rehabilitation professionals wanting to learn more about forgiveness are encouraged to enhance their understanding of it, how persons with disabilities apply it to their needs, and to explore the number of resources or training options available to them. Rehabilitation professionals have a plethora of ways they can learn about forgiveness and apply it to their clinical practice, in particular with the expansion of this topic throughout the psychology profession.

More specifically, rehabilitation professionals can read books or articles (i.e., theoretical and empirical) written by forgiveness scholars about the topic and how it can help improve peoples' lives or those written by rehabilitation scholars in an effort to illustrate its application to disability and rehabilitation counselling and psychology. ${ }^{7-9,18,34}$ Rehabilitation professionals can also enhance their understanding of forgiveness through the use of forgiveness interventions devised to teach people about forgiveness ${ }^{45}$ or forgiveness as it relates to the experience of disability (i.e., Stuntzner's Forgiveness Intervention: Learning to Forgive Yourself and Others; Stuntzner 2015b). ${ }^{37}$ Professionals can also approach the topic of forgiveness as an integrated component of interventions designed to improve coping and resilience. Stuntzner and Hartley ${ }^{38}$ developed a resilience intervention that incorporates a module on forgiveness and exposes people with disabilities to the skill of forgiveness as a means to improve resilience (i.e., Stuntzner \& Hartley's Life Enhancement Intervention: Developing Resiliency Skills Following Disability). Additionally, rehabilitation professionals can attend professional conferences (i.e., APA, ARCA, ACA, NCRE, NCRA, and NRA) or trainings that offer continuing education on the topic of forgiveness. The more professionals learn about forgiveness, the easier it will be to conceptualize and apply forgiveness to the needs and issues of persons with disabilities.

Another option is for professionals to review and familiarize themselves with forgiveness resources, websites/Facebook accounts (i.e., http://www.facebook.com/internationalforgiveness), forgiveness interventions and strategies, or forgiveness assessment instruments. Similar to the people rehabilitation professionals serve and assist, learning about forgiveness, its application and relevance to one's life, and forgiveness cultivation takes time and is not always easy, but the more professionals understand forgiveness and its importance to persons with disabilities and the rehabilitation profession, the easier it will be to implement. ${ }^{46-51}$

\section{Funding}

None

\section{Acknowledgements}

None.

\section{Conflicts of interest}

The author declares no conflict of interest.

\section{References}

1. Neenan M, Dryden W. Understanding and developing resilience. In: M Neenan \& S Palmer, editors. Cognitive behavioral coaching in practice. 2012;133-152.

2. White B, Driver S, Warren AM. Considering resilience in the rehabilitation of people with traumatic disabilities. Rehabilitation Psychology. 2008;53(1):9-17.

3. Baskin TW, Enright RD. Intervention studies on forgiveness: A metaanalysis. Journal of Counseling and Development. 2004; 82:79-90.

4. Stratton SP, Dean JB, Nonneman AJ, et al. Forgiveness interventions as spiritual development strategies: Comparing forgiveness workshop training, expressive writing about forgiveness, and retested controls. Journal of Psychology and Christianity. 2008;27(4):347-357.

5. Toussaint LL, Williams DR. National survey results for protestant, catholic, and nonreligious experiences of seeking forgiveness and of forgiveness of self, of others and by God. Journal of Psychology and Christianity. 2008;27(2):120-130.

6. Worthington EL, Langberg D. Religious considerations and selfforgiveness in treatment complex trauma and moral injury in present and former soldiers. Journal of Psychology and Theology. 2012;40(4):274 288.

7. Stuntzner S, Dalton J. Living with a disability: A gateway to practicing forgiveness and compassion. Annals of Psychotherapy and Integrative Health, December Issue. 2014.

8. Stuntzner S, Hartley M, Lynch R, et al. Comparison of two on-line interventions to cope with spinal cord injury: A pilot study. Annals of Psychotherapy and Integrative Health. 2015;1-20.

9. Webb JR. Spiritual factors and adjustment in medical rehabilitation: Understanding forgiveness as a means of coping. Journal of Applied Rehabilitation Counseling. 2003;34(3):16-23.

10. Enright RD, Fitzgibbons RP. Forgiveness therapy: An empirical guide for resolving anger and restoring hope. $2^{\text {nd }}$ ed. Washington DC: American Psychological Association. 2015.

11. Webb JR, Bumgarner DJ, Conway-Williams El, et al. A consensus definition of self-forgiveness: Implications for assessment and treatment. Spirituality in Clinical Practice. 2017;4(3):216-227.

12. Worthington EL. Initial questions about the art and science of forgiving. In: EL Worthington, editor. Handbook of forgiveness. 2005:1-13.

13. Berecz, JM. All that glitters is not gold: Bad forgiveness is counseling and preaching. Pastoral Psychology. 2001;49:253-275.

14. Freedman S. What it means to forgive and why the way in which we define forgiveness matters. Peace and Conflict. 2011;17: 334-338.

15. Enright RD. The forgiving life: A pathway to overcoming resentment and creating a legacy of love. Washington, DC: American Psychological Association. 2012.

16. Shook M. The Therapeutic triad of disability: forgiveness, selfcompassion, and resilience with Susan Stuntzner and Angela MacDonald (Part 1). The Thoughtful Counselor; 2018.

17. Svalina SS, Webb JR. Forgiveness and health among people in outpatient physical therapy. Disability and Rehabilitation. 2012; 34(5):383-392.

18. Stuntzner S. Living with a disability: Finding peace amidst the storm. Ahmedabad, Gurat, India: Counseling Association of India. 2012.

19. Stuntzner S, MacDonald A. Developing resiliency skills following disability: An intervention to assist persons with disability in learning 
to adjust to disability and with overall coping. Unpublished data from research study approved by the University of Idaho. Institutional Review Board. 2014.

20. Stuntzner S. Comparison of two self-study online interventions to promote psychological well-being in people with spinal cord injury: A forgiveness intervention and a coping effectively with spinal cord injury intervention. Dissertation Abstracts International. 2008.

21. Worthington EL, Kurusu TA, Collins W, et al. Forgiveness usually takes time: A lesson learned by studying interventions to promote forgiveness. Journal of Psychology and Theology. 2000;28(1):3-21.

22. North J. Wrong doing and forgiveness. Philosophy. 1987;62:499-508.

23. Frankl V. Man's search for meaning: An introduction to logotherapy. New York: Washington Square Press. 1969.

24. Hansen MJ, Enright RD, Baskin TW, et al. A palliative care intervention in forgiveness therapy for elderly terminally-ill cancer patients. Journal of Palliative Care. 2009;25:51-60.

25. Osterndorf CL, Enright RD, Holter AC, et al. Treating adult children of alcoholics through forgiveness therapy. Alcoholism Treatment Quarterly. 2011;29:274-292.

26. Stuntzner S, Lynch R, Enright R, et al. Forgiveness and psychosocial reactions to disability: a pilot study to examine change in persons with spinal cord injury. Int Phys Med Rehab J. 2019;4(4):171-177.

27. Waltman MA, Russell DC, Coyle CT, et al. The effects of a forgiveness intervention on patients with coronary artery disease. Psychology and Health. 2009;24(1):11-27.

28. Lee Y, Enright RD. A forgiveness intervention for women with fibromyalgia who were abused in childhood: A pilot study. Spirituality in Clinical Practice. 2014;1(3):203-217.

29. Farley AM. Predicting resiliency after brain injury: The relationship of forgiveness and religious coping. Dissertation Abstracts International. 2011.

30. Witvliet CVO, Phipps KA, Feldman ME, et al. Posttraumatic menta and physical correlates of forgiveness and religious coping in military veterans. Journal of Traumatic Stress. 2004;17(3):269-273.

31. Carson JW, Keefe FJ, Veeraindar G, et al. Forgiveness and chronic low back pain: A preliminary study examining the relationship of forgiveness to pain, anger, and psychological distress. The Journal of Pain. 2005;6(2):84-91.

32. Friedberg JP, Suchday S, Srinivas VS. Relationship between forgiveness and psychological and physiological indices in cardiac patients. International Journal of Behavioral Medicine. 2009;16:205-211.

33. Willmering P. Forgiveness as a self-reported factor in adjustment to disability. (Doctoral dissertation, University of Wisconsin - Madison). Dissertation Abstracts International. 1999;60(6-B):3009.

34. Webb JR, Touissant L, Kalpakjian CZ, et al. Forgiveness and health related outcomes among people with spinal cord injury. Disability and Rehabilitation. 2010;32(5):360-366.
35. Park CL. Making sense of the meaning literature: An integrative review of meaning making and its effects on adjustment to stressful life events. Psychological Bulletin. 2010;136(2):257-301.

36. Kurtz E, Ketcham K. The spirituality of imperfection: Storytelling and the journey to wholeness. New York, NY: Bantam Books. 1992.

37. Stuntzner S. Stuntzner's forgiveness intervention: Learning to forgive yourself and others. Ahmedabad, Gurat, India: Counseling Association of India. 2015b.

38. Stuntzner S, Hartley M. Stuntzner and Hartley's life enhancement intervention: developing resiliency skills following disability. Ahmedabad, Gurat, India: Counseling Association of India. 2014.

39. Stuntzner S, Dalton J. Forgiveness and disability: Reconsideration of forgiveness as a vital component of the rehabilitation counseling profession. Journal of Applied Rehabilitation Counseling. 2015;46(3):3544

40. Smart J. Disability, society, and the individual. 2nd ed. Austin, TX: PROED. 2009.

41. Marini I, Glover-Graf NM, Millington MJ. Psychosocial aspects of disability: Insider perspectives and counseling strategies. New York, NY: Springer Publishing. 2012.

42. Stuntzner S. Resiliency and coping with disability: The family after. Ahmedabad, Gurat, Counseling Association of India. India: 2015a.

43. Fitzgibbons RP. Anger and the healing power of forgiveness. A psychiatrist's view. In: RD Enright \& J North, editors. Exploring forgiveness. Madison, WI: University of Wisconsin Press. 1998:63-74.

44. North J. The ideal of forgiveness: A philosopher's exploration. In: RD Enright \& J North, editors, Exploring forgiveness. Madison. WI: The University of Wisconsin Press. 1988:15-34.

45. Enright RD. Forgiveness is a step-by-step process for resolving anger and restoring hope. Washington, DC: American Psychological Association. 2001

46. http://www.facebook.com/internationalforgiveness.

47. Lane NJ. A theology of anger when living with a disability. In RP Marinelli \& AE Dell Orto, editors. 4th ed. The psychological and social impact of disability.1999;173-186.

48. Smedes LB. Forgive and forget: Healing the hurts we don't deserve. San Francisco: Harper and Row. 1984

49. Stuntzner S, Dalton JA. Behavioral health service delivery among persons with disabilities. In: L Benuto \& J Singer, editors. Handbook for cultural factors in behavioral health: A guide for the helping professionals. Springer Publishing.

50. Stuntzner S, Dalton J, MacDonald A. The therapeutic triad of disability. Counseling Today. 2018;46-51.

51. White B, Driver S, Warren AM. Resilience and indicators of adjustmen during rehabilitation from spinal cord injury. Rehabilitation Psychology. 2010;55(1):9-17. 